Ethiopian Journal of Environmental Studies \& Management 7(4): 402 - 410, 2014.

ISSN:1998-0507

doi: http://dx.doi.org/10.4314/ejesm.v7i4.7

Submitted: April 10, 2014

Accepted: July 03, 2014

\title{
RELATIONSHIP BETWEEN ANTHROPOGENIC ACTIVITIES AND OCCURRENCE OF THE CHIMPANZEES (Pan troglodytes) IN OLUWA FOREST RESERVE, NIGERIA
}

\author{
${ }^{*}$ OLANIYI, O.E ${ }^{1}, 3$, OGUNJEMITE, B.G. ${ }^{1}$ AND DANSU, E.J. ${ }^{2}$ \\ ${ }^{1}$ Department of Ecotourism and Wildlife Management, Federal University of Technology, P.M.B \\ 704, Akure, Ondo State, Nigeria \\ ${ }^{2}$ Department of Mathematical Sciences, Federal University of Technology, P.M.B 704, Akure, \\ Ondo State, Nigeria \\ ${ }^{3}$ Department of Natural Resources Management, Cuttington University, Suakoko, Bong County, \\ Liberia
}

\begin{abstract}
This study determined the intensity of anthropogenic activities that took place within the chimpanzees' distribution area in Oluwa Forest Reserve, Southwest Nigeria, and the anthropogenic activities having significant influences on the occurrence of this species. A binomial Generalized Linear Model with a logit link was employed in fitting the anthropogenic activities-Chimpanzees' occurrence relationship model. Eight human activity indicators were observed, while backward stepwise variable selection algorithm was used for selecting the most significant ones. The encounter rates per kilometer of human activity indicators in the rainy and dry seasons ranged from 0.46 to 1.84 and 0.57 to 2.53 respectively. The model had Akaike's information criterion of 22, and six anthropogenic activities were observed to have significant influences on the occurrence of chimpanzees namely; current or past agricultural activity, snareline, tree cutting/ timber extraction, regularly used human trails, matchet cuts or broken stems and bark stripping but, campsites were insignificant. Therefore, agricultural activities, timber extraction and hunting are major human threats to this disturbed enclave and their control is quite pertinent in order to curbing these environmental menaces. Control measures such as encouragement of forest guards to intensify anti-poaching and encroachment patrol, and adaptation of community- based participatory management approach in integrating the host communities of this reserve to ensure continual perpetuity of this species are necessary. These mitigating steps will bring effective and efficient management of chimpanzees towards their continued survival in the forest.
\end{abstract}

Key Words: Anthropogenic activities, Chimpanzees, Oluwa Forest, Relationship

Introduction

Interaction among anthropogenic activities, habitat and animals has become a major topic in ecology as the increasing rate of habitat alteration and species extinction had forced researchers to broaden their scope of study. Knowledge about factors influencing the distribution of organisms is among the most important in ecology (Gaston and Blackburn, 1995, 1999; Lawton, 1996). In bio-assessment, the use of biological indicators depends on being able

*Corresponding Author: Olaniyi, O.E.

Email: olaniyitobby007@gmail.com 
to discriminate the effects of anthropogenic activities on the distribution of animals (Utzinger et al., 1998). Moreover, in wildlife conservation, there is need to assess environmental data such as anthropogenic indicators of sites that might support important taxa. Knowing duly well that the occurrence or range of key species is increasingly modeled from remote data (Verlinden and Masogo, 1997; Wright et al., 2000) and likewise, changes in land use require the prediction of how target species respond (Buckland and Elston, 1993).

The populations of chimpanzees, Pan troglodytes are extremely depleting in Nigeria (Oates et al., 2003). There is no doubt that there had been large scale destruction and mismanagement of the rainforest ecosystem of Nigeria (Akachukwu, 2005), in which Oluwa Forest Reserve forms an integral part. Hunting for bushmeat and rituals, commercial logging, the conversion of forest to agricultural land for cash crops and subsistence farming, climate change and habitat fragmentation had been identified as threats to chimpanzees in most of its ranges in Southwest Nigeria (Agbelusi et al., 2000; Person and Warner, 2003; Ogunjemite and Oates, 2008; Ogunjemite, 2009; Olaniyi and Ogunjemite, 2013). Progressive habitat loss often leaves small and unconnected patches in which chimpanzees' populations are isolated and at risk (Greengrass and Ogunjemite, 2008). This had increased chimpanzees' vulnerability to human predation. This condition is assuming serious dimension thereby, posing great challenges to the survival of the species in Oluwa Forest Reserve. Therefore, this ugly phenomenon is leading to a state of almost total deprivation on Chimpanzees' population in the forest (Ogunjemite and Olaniyi, 2012).

At the large spatial scales typical of wildlife conservation, empirical presenceabsence models are often derived from survey data using correlative univariate or multivariate techniques such as discriminant analysis, logistic regression and artificial neural networks (Manel et al., 1999). Although, early anthropogenic activitiesChimpanzees' occurrence relationship models generally used statistical techniques based on $p$-values for model selection, but a recent shift had seen much greater emphasis on Akaike Information Criterion (AIC) (Burnham and Anderson, 2002). In this paper, a field evaluation was performed using real data obtained from the chimpanzees' distribution area mapped out by Ogunjemite and Olaniyi (2012). This area was confined to the central portion of the OA2 axis of Oluwa Forest Reserve - a major component of Omo Forest Cluster adjudged as one of the exceptional sites for Chimpanzees conservation in Southwest Nigeria (Morgan et al., 2011) and covered approximately $39.22 \mathrm{~km}^{2}$ representing $5.78 \%$ of the total area of the original area of the reserve (Figure 1). Using Binomial Generalized Linear Model, the relationship between anthropogenic activities and occurrence of Chimpanzees in Oluwa Forest Reserve was determined.

\section{Research Questions and Hypotheses of the Study}

The need to determine the relationship between anthropogenic activities and occurrence of Chimpanzees in Oluwa Forest Reserve had prompted the following research questions:

1. What is the intensity of anthropogenic activities taking place within the Chimpanzees distribution area in Oluwa Forest Reserve?

2. Which anthropogenic activities have significant influences the relationship between anthropogenic activities and Chimpanzees' occurrence in Oluwa Forest Reserve at the site? 


\section{Methodology \\ Study Area}

The study was conducted in OA2 region of Oluwa Forest Reserve (Figure 1), with an area of $678.06 \mathrm{~km}^{2}$ and situated within coordinates $6^{\circ} 55^{\prime}-7^{\circ} 20^{\prime} \mathrm{N}$ and $3^{\circ} 45^{\prime}-4^{\circ} 32^{\prime}$ E (Ogunjemite et al., 2006). Most rivers and streams draining this forest rise from the northern part of the forest. Notable among the rivers are Oni, Oluwa, and Ominla. The rainy season in the reserve occurs from March to November while the dry season, is from December to February. Annual rainfall ranges from 1700 to $2200 \mathrm{~mm}$. Annual mean temperature in Oluwa is averagely $26{ }^{\circ} \mathrm{C}$. Soils are predominantly ferruginous tropical, typical of the variety found in intensively weathered areas of basement complex formations in the rainforest zone of southwest Nigeria. The soils are welldrained, mature, red, stony and gravely in upper parts of the sequence. The texture of topsoil in the reserves is mainly sandy loam (Onyekwelu et al., 2008; Adeduntan, 2009). The natural vegetation of the area is tropical rainforest characterized by emergent with multiple canopies and lianas. Some of the most commonly found trees in the area include Melicia excelsa, Afzelia bipindensis, Antiaris africana, Brachystegia nigerica, Lophira alata, Lovoa trichiliodes, Terminalia ivorensis, Terminalia superba, and Triplochiton scleroxylon. However, the natural vegetation of the area except for the areas devoted to forest reserve has now been reduced to secondary re-growth forest thickets and fallow re-growth at varying stages of development or replaced by perennial and annual crops (Osunade, 1991).

\section{Data Collection}

Initial forest reconnaissance was undertaken for a period of one week in
August, 2011. This was to determine the best method for data collection and delineate the recce paths to be transverse during the study. The presence-absence data and the anthropogenic activities were obtained by direct and indirect methods. Recce survey of chimpanzees started with the establishment of three recce paths totaling $(8.70 \mathrm{~km})$ mapped out evenly within the identified core area of distribution. Enumerations were carried out for two weeks each consecutively in both rainy and dry seasons. Data collection for the rainy season was undertaken in September and October, 2011 while the dry season data collection took place in January and February, 2012. At the close of daily recce walks, calls of the species were carefully monitored in the evenings to be followed at dawn, in order to observe their nesting sites and make direct counts on the species. Also, observations of anthropogenic activities on the recce walks were undertaken. The following activities were observed and recorded namely: roads (used or disused), matchet cuts or broken stems resulting from a single, regularly used human trails, snare line - active or abandoned i.e the number of snares and data on any species in snare lines were recorded, honey extraction, camp sites - active or abandoned, fire places. An average of $13 \mathrm{hrs}$ research efforts was expended each day of enumeration. This is made up of six hours of recce walk $(7: 00 \mathrm{hr}-$ 13:00hr), four hours was spent in the evening $(15: 00 \mathrm{hr}-19: 00 \mathrm{hr})$ and three hours of activity monitoring at dawn $(2: 00 \mathrm{hr}-$ 13:00hr). This schedule was strictly followed at both seasons except on heavy raining days in wet season. These activities were planned to fall on second half of respective lunar months in order to aid visibility at dawn. 
Relationship between Anthropogenic Activities and Occurrence of...............LANIYI et al.
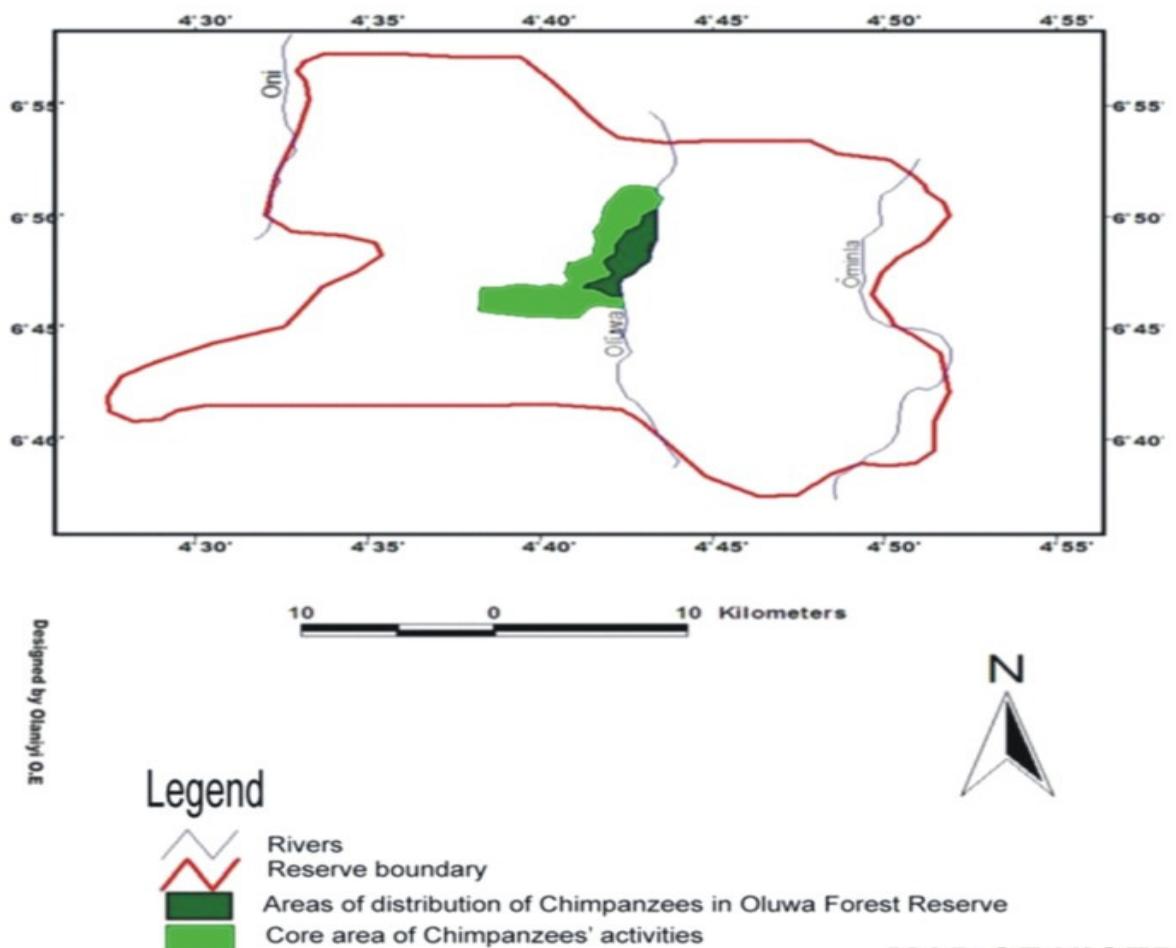

MAP OF NIGERIA

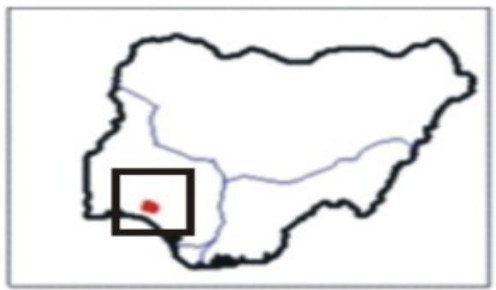

Figure 1: Current chimpanzees' distribution area in Oluwa Forest Reserve, Nigeria (Source: Ogunjemite and Olaniyi 2012)

\section{Modeling}

A binomial Generalized Linear Model with a logit link was used to determining the relationship between anthropogenic activities and Chimpanzees' occurrence in Oluwa Forest Reserve. This model investigated the hypothesis that there was an influence of the anthropogenic activities observed on the presence-absence of Chimpanzees in the study area. The dependent variables (presence-absence data) denoted in binaries ( 0 or 1$)$ were obtained and represented with the following observations; Direct sightings, footprints, dung piles and vocalization of the Chimpanzees. The independent/ environmental variables or predictors were represented with the following anthropogenic activities; Current or past agricultural activity, snareline, regularly used human trails, tree cutting/ timber extraction, roads (used or disused), bark stripping, matchet cuts or broken stems, campsite (active or abandoned), seasons and vegetation types.

The model specification with the logit link was defined as:

$\log i t(\pi)=\log _{\mathrm{e}}\left(\frac{\pi}{1-\pi}\right)=\beta_{0}+\beta_{1} x_{1}+\beta_{2} x_{2}+\beta_{3} x_{3}+\cdots+\beta_{k} x_{k}$ 
Where $\pi$ is the probability that the species will be present at site $k, \beta_{0}$ is the intercept coefficient, the $x_{k} s$ are the habitat variables, and the $\beta_{k} s$ are habitat variable coefficients.

\section{Results}

Figure 2 presented the encounter rates per kilometer of the human activity indicators within the Chimpanzees distribution during the rainy season. The encounter rates per kilometer ranged between 0.46 and 1.84 . Matchet cuts or broken stems had the highest while campsite (active or abandoned) had the least. Two activities namely roads (used or disused) and current or past agricultural activity had the same number of occurrences and were moderately high during this season (1.03). Tree cutting/ timber extraction were extremely low (0.57). Snarelines were also high (1.38).

The encounter rates per kilometer of the human activity indicators within the Chimpanzees distribution during the dry season were presented in Figure 3. It ranged between 0.57 and 2.53. Regularly used human trails had the highest while campsite (active or abandoned) had the least. The activities of tree cutting/ timber extraction and current or past agricultural activity were extremely high i.e. 2.30 and 2.41. Hunting activities using Snarelines (1.15) were moderately high as compared to the others.
Roads (used or disused), 1.72 were also high as compared to that of the rainy season.

Table 1 presents estimated coefficients and standard errors for anthropogenic activities - Chimpanzees' presence-absence relationship model in Oluwa Forest Reserve. In the model, eight anthropogenic indices were subjected to backward stepwise variable selection algorithm. Two anthropogenic activities namely campsites $(\beta=2.63 ; \mathrm{P}=$ $1.00)$ and roads $\left(\beta=-2.29 \mathrm{C} 10^{\wedge}-1 ; \mathrm{P}=0.91\right)$ had no significant influence on the occurrence of Chimpanzees in their distribution, while the remaining six anthropogenic indices namely current or past agricultural activity $\left(\beta=2.67 \times 10 ; \mathrm{P}=8.9 \times 10^{\wedge}\right.$ - 6), snareline $\left(\beta=-2.75 \times 10 ; \mathrm{P}=6.53 \times 10^{\wedge} 5\right)$, tree cutting/ timber extraction $(\beta=4.85 \times 10$; $\left.\mathrm{P}=2.20 \times 10^{\wedge}-16\right)$, regularly used human trails $(\beta=2.00 \times 10 ; \mathrm{P}=0.05)$, matchet cuts or broken stems $(\beta=-2.07 \times 10 ; \mathrm{P}=0.00)$ and bark stripping $(\beta=4.72 \times 10 ; \mathrm{P}=0.00)$ had significant influences on the occurrence of Chimpanzees in their distribution. Much more, the Akaike Information Criterion (AIC) of Model 1 was computed as 22 and the intercept $\left(\beta_{0}\right)$ as -113.60 .

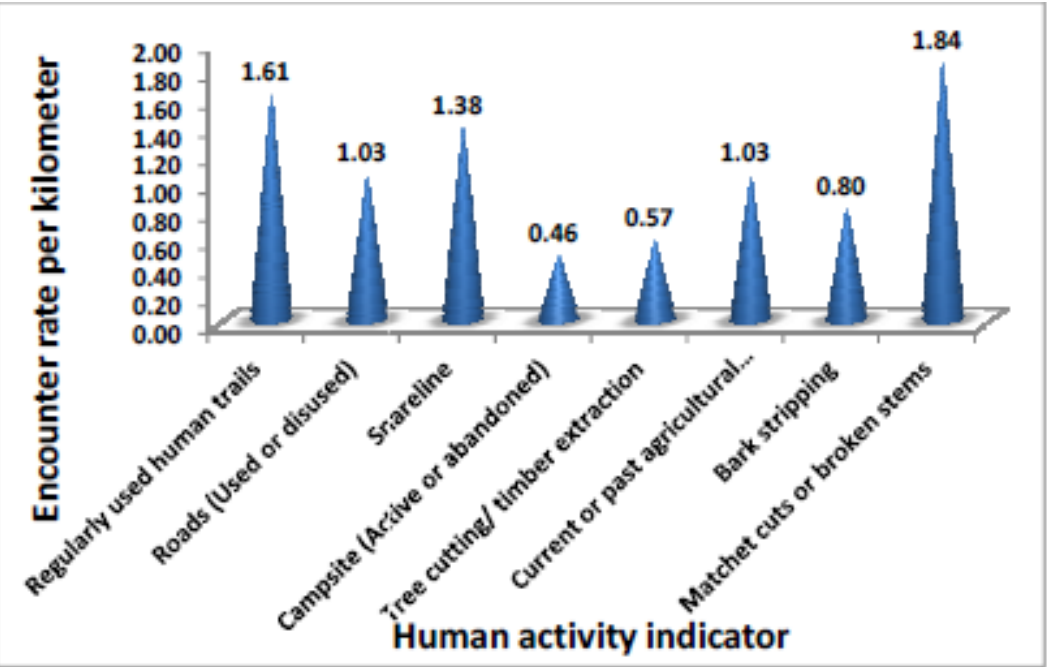

Figure 2: Encounter rate per kilometer of the human activity indicators within the Chimpanzees distribution during the rainy season 


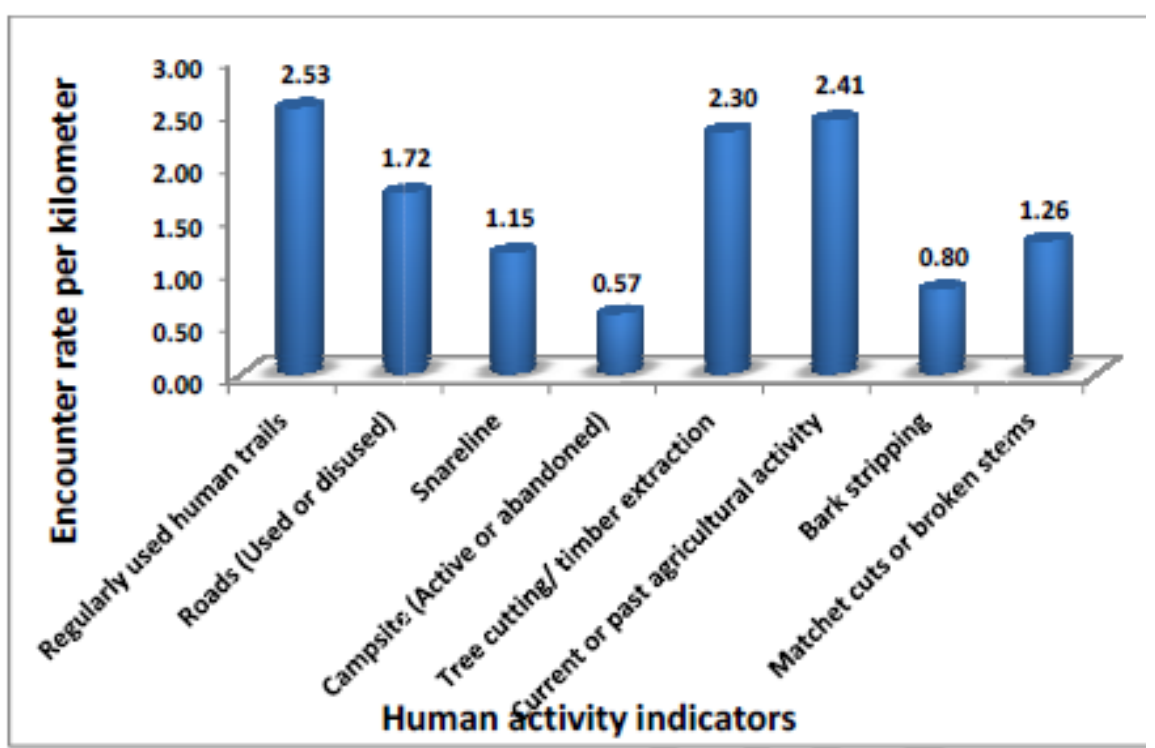

Figure 3: Encounter rate per kilometer of the human activity indicators within the Chimpanzees distribution during the dry season

Table 1: Estimated Coefficients and Standard Errors for anthropogenic activities - Chimpanzees' presence-absence relationship model in Oluwa Forest Reserve

\begin{tabular}{lccl}
\hline Variables & Estimates & Standard error & Significant level \\
\hline Current or Past Agricultural Activity & $-2.67 \times 10$ & 0.53 & $8.93 \times 10^{\wedge}-6^{*}$ \\
Snareline & $-2.70 \times 10$ & 1.35 & $6.53 \times 10^{\wedge}-5^{*}$ \\
Campsites & 2.63 & 0.50 & $1.00 \mathrm{~ns}$ \\
Tree Cutting/ Timber Extraction & $4.85 \times 10$ & 0.03 & $2.20 \times 10^{\wedge}-1^{*}$ \\
Regularly used Human Trails & $2.00 \times 10$ & 0.79 & $0.05^{*}$ \\
Roads (Used or disused) & $-2.92 \times 10^{\wedge}-1$ & 0.59 & $0.91 \mathrm{~ns}$ \\
Matchet Cuts or Broken Stems & $-2.07 \times 10$ & 1.34 & $0.00^{*}$ \\
Bark Stripping & $4.72 \times 10$ & 0.33 & $0.00^{*}$ \\
Intercept & -113.60 & 0.35 & \\
Akaike Information Criterion (AIC) & 22 & & \\
\hline
\end{tabular}

* signifies there is significant difference $(\mathrm{P}<0.05)$ while "ns" signifies there is no significant difference $(\mathrm{P}>0.05)$

\section{Discussion}

\section{Anthropogenic Activities - Chimpanzees' Occurrence Relationship Model}

In the anthropogenic activities Chimpanzees' occurrence relationship model examined, information criteria such as AIC (Akaike's Information Criterion) address this relationship by trading off explained variation against model complexity (Elith and Leathwick, 2009). Amidst various human activity indicators observed, the model revealed the most significant threats influencing the presence- absence of chimpanzees in Oluwa Forest Reserve. Moreover, current or past agricultural activity, snareline and matchet cuts or broken stems had a negative multiplier effect on the model as revealed by their estimated coefficients. This implies that an intense hunting and agricultural activity within the chimpanzees habitat will always result to a low probability of their occurrence (i.e. 
tending towards 0 ). This statement was made factual through the absence of chimpanzees in the other two compartments of the reserve i.e OA1 and OA3 compartments. These two anthropogenic activities had made the central portion of Oluwa Forest Reserve situated at OA2 compartment to contain the remaining populations of the species (Greengrass, 2009; Morgan et al., 2011; Ogunjemite and Olaniyi, 2012).

\section{Factors Affecting the Occurrence of Chimpanzees}

Anthropogenic activities are the foremost threat to chimpanzees' populations in Oluwa Forest Reserve (Olaniyi and Ogunjemite, 2013). Current or past agricultural activity, snareline, tree cutting/ timber extraction, regularly used human trails, matchet cuts or broken stems, and bark stripping were the human threat indicators observed to have significant influences on the occurrence of chimpanzees in Oluwa Forest Reserve. This further explained the earlier findings made by Greengrass (2009) and Ogunjemite (2010) that the major threats to the population of chimpanzees in Oluwa Forest Reserve are agricultural activity, hunting and timber extraction.

Furthermore, the high rate of bush clearing emanating from agricultural activities and timber extraction had resulted into forest degradation and fragmentation. As a matter of fact, this phenomenon has a great potential of restricting the mobility of certain animals and thereby isolating some populations (Andreassen et al., 1996; Schmitt and Seitz, 2002) of which the chimpanzees of Oluwa Forest Reserve are unexceptional. Loss of timber trees can contribute disproportionately to the diets of some primate species (Chapman and Peres, 2001), but the unsustainable timber extraction/ logging had posed serious threats to the food base and shelter of chimpanzees. In reality, the remaining natural forest within Oluwa
Forest Reserve had been increasingly fragmented and disturbed as a result of unregulated and unsustainable timber extraction practices (Greengrass, 2009). It has been established that once the deforestation on major scale combines with hunting, the effect on wildlife populations could be terminal (Teleki, 1989; Kormos et al., 2003). The resulting effects of these anthropogenic indicators to the chimpanzees in Oluwa Forest Reserve had been the high sensitivity of the species to presence of humans and invariably, this scared them from proper observation and assessment through direct sightings. Therefore, indirect sighting is presently the most appropriate method of studying chimpanzees in the Oluwa Forest Reserve, pending the time appropriate conservation measures are taken on the species core distribution area.

\section{Conclusion and Recommendation}

In conclusion, this work has shown that evaluating the relationship between anthropogenic activities and presence/ absence of chimpanzees is possible. The result of this research confirmed that binomial generalized linear model is capable of determining the significant influences of anthropogenic activities on the occurrence of chimpanzees in Oluwa Forest Reserve. Agricultural activities, timber extraction and hunting are major human threats to this disturbed enclave and their control is quite pertinent in order to curbing these environmental menaces. Control measures such as encouragement of forest guards to intensify anti-poaching and encroachment patrol, and adaptation of community- based participatory management approach in integrating the host communities of this reserve to ensure continual perpetuity of this species are necessary. These mitigating steps will bring effective and efficient management 
of chimpanzees towards their continued survival in the forest.

\section{References}

Adeduntan, S.A. (2009). Diversity and abundance of soil mesofauna and microbial population in South-Western Nigeria. African Journal of Plant Science, 3 (9): 210-16.

Agbelusi, E.A., Ogunjemite, B.G. and Owolabi, O.O. (2000). Utilization pattern and conservation of primates in Ondo and Ekiti States, Nigeria. The Bioprospector, 2(1): 9-14.

Akachukwu, A.E. (2005). Disappearing Forests, the Consequences and Challenges of Sustainable Development in Nigeria", Proceedings of the 31 st Annual Conference of the Forestry Association of Nigeria held at University of Agriculture Makurdi. November 20-25 49-57.

Andreassen, H.P., Halle, S. and Ims, R.A. (1996). Optimal width of movement corridors for root voles: not too narrow and not too wide. Journal of Applied Ecology, 33: 63-70.

Buckland, S.T. and Elston, D.A. (1993). Empirical models for the spatial distribution of wildlife. Journal of Applied Ecology, 30: 478-95.

Chapman, C.A. and Peres, C.A. (2001). Primate Conservation in the new millennium: the role of scientists. Evolutionary Anthropology, 10: 16-33.

Elith, J. and Leathwick, J.R. (2009). Species Distribution Models: Ecological Explanation and Prediction across Space and Time. Annual Review of Ecology, Evolution, and Systematic, 40: 677-97.

Gaston, K.J. and Blackburn, T.M. (1995). Mapping biodiversity using surrogates for species richness - macro-scales and new world birds. Proceedings of the
Royal Society of London, Series $B$. Biological Science, 262: 335-41.

Greengrass, E.J. (2009). Chimpanzees are Close to Extinction in Southwest Nigeria. Primate Conservation, 24: 7783.

Kormos, R., Boesch, C., Bakarr, M.L. and Butynski, T.M. (2003). African Chimpanzees: Status Survey and Conservation Action Plan. IUCN, Gland, Switzerland p1- 219.

Lawton, J. (1995). Patterns in ecology. Oikos 75: $145-47$.

Manel, S., Dias, J.M. and Ormerod, S.J. (1999). Comparing discriminant analysis, neural networks and logistic regression for predicting species' distributions: a case study with a Himalayan river bird. Ecological Modeling 120: 337-47.

Morgan, B.J., Adeleke, A., Bassey, T., Bergl, R., Dunn, R., Fotso, R., et al. (2011). Regional Action Plan for the Conservation of the Nigeria- Cameroun Chimpanzees (Pan troglodytes ellioti), IUCN/ SSC Primate Specialist Group and Zoological Society of San Diego, CA, USA p52.

Oates, J.F., Gadsby, .L, Jenkins, P., Gonder, K., Bocian, C. and Adeleke, A. (2003). Chimpanzees in Nigeria and their habitats. In: Status Survey and Conservation Action Plan:West African Chimpanzees R. Kormos C, Boesch MI, Bakarr, Butynski TM. IUCN, Gland, Switzerland and Cambridge, UK p57.

Ogunjemite, B.G., Agbelusi, E.A., Afolayan, T.A. and Onadeko, S.A. (2006). Status Survey of Chimpanzee in the Forest Zone of Southwestern Nigeria. Acta Zoologica Sinica, 52: 1009 - 14.

Ogunjemite, B.G. and Oates, J.F. (2008). Assessment of the chimpanzee populations in Akure-Ofosu and AyedeIsan Forest reserves, Southwestern 
Nigeria. Report to Conservation International, Arlington, VA p12.

Ogunjemite, B.G. and Olaniyi, O.E. (2012). The Chimpanzees of Oluwa Forest Reserve, Southwestern Nigeria. International Journal of Development and Sustainability, 1:3 (In press). www.isdsnet.com/ijds-v1n3-15.pdf

Ogunjemite, B.G. (2009). The effects of habitat fragmentation and hunting on Chimpanzees of Gashaka- Mambilla region, Nigeria, Forests and Forest Products Journal, 2: 47- 56.

Olaniyi, O.E. and Ogunjemite, B.G. (2013). The quantification of threats to Chimpanzees' habitat of Oluwa Forest Reserve, Southwest Nigeria. Proceedings of 4th Annual Biodiversity Conference on sustaining the remaining tropical biodiversity held at University of Lagos, Lagos, 3rd- 4th September pp112- 16.

Onyekwelu, J.C., Mosandl, R. and Stimm, B. (2008). Tree species diversity and soil status of primary and degraded tropical rainforest ecosystems in SouthWestern Nigeria. Journal of Tropical Forest Science, 20(3): 193-204.

Osunade, M.A.A. (1991). Agricultural change by supplanting process in a traditional farming System.
International Journal of Ecology and Environmental Science, 17: 201-9.

Person, H.M. and Warner, M.D. (2003). The chimpanzees and other primates of Omo Forest Reserve. The Nigerian Field, 68: 160-67.

Teleki, G. (1989). Population status of wild chimpanzees (Pan troglodytes) and threats to survival in: Understanding Chimpanzees (eds. P.G. Heltne and L.A. Marquardt). Harvard University Press, Cambridge, Massachusetts, USA pp. 312-53.

Utzinger, J., Roth, C. and Peter, A. (1998). Effects of environmental parameters on the distribution of bullhead Cottus gobio with particular consideration of the effects of obstructions. Journal of Applied Ecology, 35: 882-92.

Verlinden, A. and Masogo, R. (1997). Satellite remote sensing of habitat suitability for ungulates and ostrich in the Kalahari of Botswana. Journal of Arid Environment, 35: 563-74.

Wright, A., Fielding, A.H. and Wheater, C.P. (2000). Predicting the distribution of European badger (Meles meles) setts over an urbanized landscape: a GIS approach.

Photogrammetric Engineering and Remote Sensing, 66: 423-28. 